\title{
Are Heart Rate and Rating of Perceived Exertion Effective to Control Indoor Cycling Intensity?
}

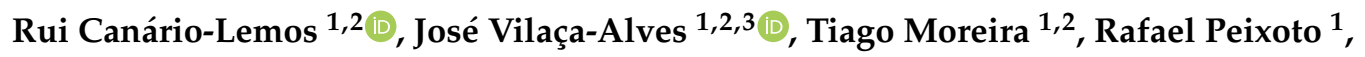 \\ Nuno Garrido ${ }^{1,3, * \mathbb{D}}$, Fredric Goss ${ }^{4}$, Hélio Furtado ${ }^{5}$ and Victor Machado Reis ${ }^{1,2,3}$ \\ 1 Department, of Sports Sciences, Exercise and Health, University of Trás-os-Montes e Alto Douro, \\ 5001-801 Vila Real, Portugal; Ruimaldini27@hotmail.com (R.C.-L.); josevilaca@utad.pt (J.V.-A.); \\ tromoreira@hotmail.com (T.M.); peixoto347@gmail.com (R.P.); victormachadoreis@gmail.com (V.M.R.) \\ 2 Research Group in Strength Training and Fitness Activities, GEETFAA, 5001-801 Vila Real, Portugal \\ 3 Research Center in Sports Sciences, Health Sciences and Human Development, CIDESD, \\ 5001-801 Vila Real, Portugal \\ 4 Department of Health and Physical Activity, University of Pittsburgh, Pittsburgh, PA 15260, USA; \\ goss@pitt.edu \\ 5 Health School: Physical Education, University Castelo Branco, UCB, Campus Realengo, \\ Rio de Janeiro 21710-255, Brazil; heliofurtado@uol.com.br \\ * Correspondence: ndgarrido@gmail.com
}

Received: 27 May 2020; Accepted: 2 July 2020; Published: 4 July 2020

\begin{abstract}
Indoor cycling's popularity is related to the combination of music and exercise leading to higher levels of exercise intensity. It was our objective to determine the efficacy of heart rate and rating of perceived exertion in controlling the intensity of indoor cycling classes and to quantify their association with oxygen uptake. Twelve experienced males performed three indoor cycling sessions of $45 \mathrm{~min}$ that differed in the way the intensity was controlled: (i) oxygen uptake; (ii) heart rate; and (iii) rating of perceived exertion using the OMNI-Cycling. The oxygen uptake levels were significantly higher $\left(p=0.007 ; \mu_{\mathrm{p}}^{2}=0.254\right)$ in oxygen uptake than heart rate sessions. Oxygen uptake related to body mass was significantly higher $(p<0.005)$ in the oxygen uptake sessions compared with other sessions. Strong correlations were observed between oxygen uptake mean in the oxygen uptake and rating of perceived exertion sessions $(r=0.986, p<0.0001)$ and between oxygen uptake mean in the oxygen uptake and heart rate sessions $(r=0.977, p<0.0001)$. Both heart rate and rating of perceived exertion are effective in controlling the intensity of indoor cycling classes in experienced subjects. However, the use of rating of perceived exertion is easier to use and does not require special instrumentation.
\end{abstract}

Keywords: OMNI Cycle scale; oxygen uptake; group class

\section{Introduction}

The practice of indoor cycling (IC) is a very common group activity in gyms and health clubs. One of the goals of the practice of IC is to improve some parameters, for example, body composition, a decrease in body mass, in fat free mass, an improvement in muscle mass, a decrease in body perimeter (ex. calf, thigh, abdominal, chest, and arm size), a decrease in resting heart rate (HR), and also an improvement in oxygen uptake $\left(\mathrm{VO}_{2}\right)$. In order to maximize the benefits and minimize the risks, controlling intensity in IC classes is very important. In these classes, intensity control can be carried out through heart rate (\% of maximum or reserve), metabolic equivalents, oxygen uptake, power output, and rate of perceived exertion (RPE) [1].

$\mathrm{HR}$ is the variable most frequently recommended for controlling intensity in IC [2,3]. However, besides the variations of the intensity of the exercise [4,5], there are multiple factors that can 
bias the HR, thus the HR can increase or decrease without intensity being the direct cause. These factors include cycling rhythm [6,7], ambient temperature [8,9], state of hydration [10], and music stimuli [11]. In contrast, studies have shown that there is no impact on HR when exercise is carried out in environments with sound and visual stimuli [12] and with various states of hydration. [13] As for how HR responds to exercise intervals, there is a consensus that responses to intensity change are comparatively slow, contrary to continuous efforts with constant intensity [14].

Measures of metabolic rate, namely $\mathrm{VO}_{2}$, are precise indicators in establishing exercise intensity. However, the equipment required to measure $\mathrm{VO}_{2}$ is expensive and may be available only in a laboratory environment. Power output is one of the most reliable forms of controlling effort intensity in cycling [15]. In order for power output to be determined, there is a need to quantify the cycling cadence, and the resistance applied to the bike or the force applied to the pedal, as well as the flywheel circumference or, alternatively, to have a power meter fitted to the crank, crank arm, or pedal. This requires expensive equipment, which is normally not available in places where indoor cycling is practiced for recreational purposes and to improve health and performance. On the other hand, the use of RPE is an easy and inexpensive way to self-regulate intensity [16]. This method allows for anatomical differentiation of the exertion signal associated with the legs and chest as well as the global or whole-body perception of exertion [17]. The most frequently used RPE scales are the Borg (6-20), the Borg CR-10 (0-10), and the OMNI-Cycle scale (0-10) [18]. These RPE scales have been shown to be reliable in the control of exercise intensity during cycling for men and women $[19,20]$ who are familiar with the effort scale and with the exercise mode [21]; however, some authors assert that exercise intensity control during IC is best carried out through the use of HR [3-5,22].

Therefore, due to these discrepancies in the literature, the aim of this study was to determine if the use of heart rate and rating of perceived exertion are effective means to control the intensity of indoor cycling classes and to quantify their association with oxygen uptake.

This study is pertinent because there is a lack of consensus in the existing literature concerning the safety of IC, as the intensity has been shown to exceed the levels of maximum effort reached in the laboratory $[4,5]$. Therefore, it is important to find a safe and effective way to self-regulate intensity during IC.

\section{Methods}

\subsection{Experimental Design}

Each participant was involved in five sessions. During their first visit to the laboratory, the participants underwent a series of anthropometric measurements (body mass, height, and estimated body fat). In the same session, their $\mathrm{VO}_{2}$ peak was measured on a cycle ergometer (Monark ergomedic $839 \mathrm{E}$, Vansbro, Sweden), using a ramp test with an incremental load protocol [23]. $\mathrm{VO}_{2}$, carbon dioxide production $\left(\mathrm{VCO}_{2}\right)$, and ventilation (VE) were measured using the portable device $\mathrm{K}_{4} \mathrm{~b}^{2}$ (Cosmed $\mathrm{K}_{4}$, Roma, Italy) at standard temperature, pressure, dry (STPD) conditions in relation to the testing conditions. Seventy-two hours later, a retest was performed in order to confirm the levels obtained during the first test. The three following experimental sessions were random and were performed at the same time of day (8:30 a.m.) with seven-day rest intervals between each one. These sessions consisted of $45 \mathrm{~min}$ of IC, differing only in the method used to control intensity (HR, RPE, and the load corresponding to the ventilatory thresholds I and II, and to $90 \%$ of $\mathrm{VO}_{2}$ peak). In all sessions, resting metabolic rate (RMR) was measured $45 \mathrm{~min}$ prior to IC and in the recovery period following exercise. $\mathrm{VO}_{2}$ levels were collected before (to establish RMR), during, and $30 \mathrm{~min}$ after each experimental session (to measure $\mathrm{VO}_{2}$ during the recovery). All participants were requested to not perform any type of exercise, nor ingest alcohol and/or caffeine in the preceding $72 \mathrm{~h}$ or during the experimental sessions. Subjects were told to keep their regular nutrition and were asked to record their food intake in the $24 \mathrm{~h}$ preceding the first session and to replicate it on each day prior to the other two sessions. All participants reported to the experimental sessions having fasted for at least $12 \mathrm{~h}$. 


\subsection{Participants}

The participants were 12 Caucasian males $26.83 \pm 5.10$ years old, with $77.75 \pm 9.52 \mathrm{~kg}$ of body mass, $177.75 \pm 5.69 \mathrm{~cm}$ height, $16.12 \pm 2.37 \%$ of estimated fat, $39.75 \pm 6.10 \mathrm{~mL} / \mathrm{kg} / \mathrm{min} \mathrm{of} \mathrm{VO}_{2}$ $\max$, and $4.08 \pm 0.70 \mathrm{~mL} / \mathrm{kg} / \mathrm{min}$ of $\mathrm{VO}_{2}$ resting. They had $20.75 \pm 12.36$ months of experience in IC. The inclusion criteria were no positive responses to the physical activity readiness questionnaire (PAR-Q) test [24], administrated during the first laboratory session; not taking any medication or supplements that could interfere with the variables of this study, and no osteoarticular or musculotendinous injury. After clarifying all questions and concerns, and after agreeing to take part in the study, each participant freely signed a declaration of consent in accordance with the Helsinki Declaration. This study was approved by the institution's committee for ethics in research with the protocol n. 28/2017.

\subsection{Experimental Sessions}

The three experimental sessions began with 30 min of RMR assessment in a fasting condition. RMR was measured by indirect calorimetry using COSMED ${ }^{\circledR} \mathrm{K}_{4} \mathrm{~b}^{2}$. The measurement was performed in an isolated room, with the door closed, and the lights dimmed. RMR was then measured for $30 \mathrm{~min}$. $\mathrm{RMR}$ was determined from steady-state $\mathrm{VO}_{2}$ values during the last 25 min of measurement.

Participants ate a standard meal after measuring the RMR, and then waited another 30 min before starting the experimental session. The standard meal provided consisted of a $242 \mathrm{kcal}$ snack consisting of $330 \mathrm{~mL}$ of water, $350 \mathrm{~mL}$ of orange juice, and a $60 \mathrm{~g}$ energy bar (Protein Chox Lemon Crunch Myprotein, Northwich, UK), which provided $22 \mathrm{~g}$ protein, $23 \mathrm{~g}$ carbohydrate, and $8 \mathrm{~g}$ fat. Each IC session consisted of 45 min on a cycle ergometer (Monark ergomedic 839 E, Vansbro, Sweden) and was divided into several musical tracks with different intensities. The IC sessions consisted of 11 music tracks, which were divided into warm-up (track 1), main phase (tracks 2-10), and cooldown (track 11) (see Table 1). Exercise intensity in the three experimental sessions was set using $\mathrm{VO}_{2}, \mathrm{HR}, \mathrm{or} \mathrm{RPE}$ as follows: (i) at $90 \%$ of peak $\mathrm{VO}_{2}$, at ventilatory threshold I (VTI) and at ventilatory threshold II (VTII) (3 pre-defined intensities for various tracks in the $\mathrm{VO}_{2}$ session); (ii) at $90 \%, 70 \%, 50 \%$, and $40 \%$ of maximum HR (4 pre-defined intensities for various tracks in the HR session), and; (iii) at 2, 4, 6, and 8 of the OMNI-Cycle scale (4 pre-defined intensities for various tracks in the RPE session).

Table 1. Planning of the $45 \mathrm{~min}$ of indoor cycling in the three sessions.

\begin{tabular}{|c|c|c|c|c|c|c|}
\hline Track & Time & ВPM & RPM & RPE < (OMNI 0-10) & HR (\% HRmax) & $\begin{array}{c}\mathrm{VO}_{2} \text { (Thresholds and } \% \mathrm{VO}_{2} \\
\text { Peak) }\end{array}$ \\
\hline 1 & $5: 00$ & 80 & $80 / 60$ & 2 & $40 \%$ & VTI \\
\hline 2 & 3:00 & 80 & $80 / 60$ & 4 & $50 \%$ & VTI \\
\hline 3 & 5:00 & 120 & 60 & 6 & $70 \%$ & VTII \\
\hline 4 & 6 & 120 & 60 & $\begin{array}{c}\text { Interval } \\
1 \text { min at } 6 \\
\text { with } \\
1 \text { min at } 8\end{array}$ & $\begin{array}{c}\text { Interval } \\
1 \text { min at } 70 \% \\
\text { with } \\
1 \text { min at } 90 \%\end{array}$ & $\begin{array}{c}\text { Interval } \\
1 \text { min at VTII } \\
\text { with } \\
1 \text { min at } 90 \%\end{array}$ \\
\hline 5 & $2: 30$ & 80 & $80 / 60$ & 4 & $50 \%$ & VTI \\
\hline 6 & $3: 30$ & 120 & 60 & 6 & $70 \%$ & VTII \\
\hline 7 & 5.00 & 120 & 60 & $\begin{array}{c}\text { Interval } \\
30 \mathrm{~s} \text { at } 6 \\
\text { with } \\
30 \mathrm{~s} \text { at } 8\end{array}$ & $\begin{array}{c}\text { Interval } \\
30 \text { s at } 70 \% \\
\text { with } \\
30 \text { s at } 90 \%\end{array}$ & $\begin{array}{c}\text { Interval } \\
30 \mathrm{~s} \text { at VTII } \\
\text { with } \\
30 \mathrm{~s} \text { at } 90 \%\end{array}$ \\
\hline 8 & $4: 30$ & 80 & $80 / 60$ & 4 & $50 \%$ & VTI \\
\hline 9 & 3:30 & 120 & 60 & 6 & $70 \%$ & VTII \\
\hline 10 & 5.00 & 120 & 60 & $\begin{array}{c}\text { Interval } \\
1 \text { min at } 6 \\
\text { with } \\
1 \text { min at } 8\end{array}$ & $\begin{array}{c}\text { Interval } \\
30 \text { s at } 70 \% \\
\text { with } \\
30 \text { s at } 90 \%\end{array}$ & $\begin{array}{c}\text { Interval } \\
30 \text { s at VTII } \\
\text { with } \\
30 \text { s at } 90 \%\end{array}$ \\
\hline 11 & 2:00 & 80 & $80 / 60$ & 2 & $40 \%$ & VTI \\
\hline
\end{tabular}

VTI-ventilatory threshold I; VTII—ventilatory threshold II; BPM-beats per minute; RPM-rotations per minute; RPE-rating of perceived exertion; $\mathrm{HR}$ - heart rate; $\mathrm{VO}_{2}$ - oxygen uptake. 


\subsection{Measurements}

For height measurement, a stadiometer (Sanny ES 2030, American Medical do Brasil, Ltd., São Paulo, Brazil) was used. The height was defined as the distance, in a straight line, between the uppermost point of the skull and the lowest point (in this case, the floor where the feet were placed), with the subject in an anthropometric (erect) position. That is, by drawing an imaginary line (using an object as a linear example: ruler) that passes through the lower point of the lower edge of the right eye orbit and the highest point on the upper side of the corresponding external auditory meatus. The subjects stood barefoot, with the heels together, forming a " $\mathrm{V}$ " with the feet and the coccyx, a dorsal column, and a posterior part of the head in contact with the stadiometer. The reading was expressed in centimeters to the tenths and recorded after a deep inspiration.

An electronic scale was used to assess the body mass (Tanita BF-562, Tanita Europe B. V., Yiewsley Middlesex, UK), where subjects wore only shorts and stood barefoot in the center of the platform of the scale and remained immobile until stabilization of the scale digits. Body mass was expressed in $\mathrm{kg}$ to the nearest tenths.

Corporal density was calculated by measuring the skinfold thickness, at the following sites: pectoral, middle axillary, triceps, subscapular, abdominal, suprailiac, and crural, using an adipometer (Sanny AD 1010, American Medical do Brasil, Ltd.a, São Paulo, Brasil) [25] and converted into body fat with an equation [26].

For measuring $\mathrm{VO}_{2}$ peak and calculating ventilatory thresholds I and II, a portable aerobic metabolic cart was used (Cosmed K4, Roma, Italy), the metabolic cart was calibrated before each session. A cycle ergometer (Monark ergomedic 839 E, Vansbro, Sweden) was used with the protocol defined by [23]. The test began with a load of 50 watts (W) and was increased by $25 \mathrm{~W}$ every two minutes until exhaustion. The cycling cadence was maintained at $60 \mathrm{rpm}$ with a metronome and monitor during the test. The inability of the participant to maintain the cadence for a period of $5 \mathrm{~s}$ was used as the criterion for test termination. Verbal encouragement by a single individual was used during each test in order to motivate the participants to maximal exhaustion. The determining of individual levels of $\mathrm{VO}_{2}$ peak and of ventilatory thresholds I (VTI) and II (VTII), were carried out independently by analyzing responses from the two tests (test and retest with $72 \mathrm{~h}$ between them). When the two investigators did not agree, (agreement level $\geq 95 \%$ ), a third investigator was recruited. The highest level of relative $\mathrm{VO}_{2}$ obtained during the tests was determined to be $\mathrm{VO}_{2}$ peak. The VTI was determined using the lowest value of the ratio between ventilation (VE) and $\mathrm{VO}_{2}\left(\mathrm{VE} / \mathrm{VO}_{2}\right)$. The VTII was established as the point where the ratio between VE and the production of carbon dioxide $\left(\mathrm{VE} / \mathrm{VCO}_{2}\right.$ ) rose exponentially.

HR was obtained through all testing sessions by placing an HR monitor (Wireless Double Electrode, Polar ${ }^{\circledR}$, Kempele, Finland) on the participant's chest. HR was measured continuously during each test. During the tests to establish $\mathrm{VO}_{2}$ peak, maximum $\mathrm{HR}$ was also obtained. The highest value observed in the ramp test was considered the individual's maximal HR. The values corresponding to $40 \%, 50 \%$, $70 \%$, and $90 \%$ of maximum HR obtained in the ramp test were used in the sessions controlled by HR.

Prior to the experimental sessions and during the maximal test, the participants were familiarized with the OMNI-Cycle scale. The scale uses figures, numbers from 0-10, with verbal descriptors ranging from easy to extremely hard. The participants were informed that there are no incorrect or correct responses and that RPE should reflect the degree of effort that they feel at that moment. In the sessions in which intensity load was controlled by RPE, the values 2 (easy), 4 (somewhat easy), 6 (somewhat hard), and 8 (hard) were used for each intensity change.

\subsection{Statistical Analyses}

An exploratory analysis was performed on all data. A graphic observation was carried out with the goal of detecting possible outliers and incorrect data input of all the used variables. The interclass correlation coefficient was used to test the reliability in the measurement of the levels of $\mathrm{VO}_{2} \mathrm{while}$ resting, the load that corresponded to the first VTI and the VTII, the load corresponding to $90 \%$ of 
peak $\mathrm{VO}_{2}$, and maximal HR. The data were shown to be normally distributed (Shapiro-Wilk test). Sphericity was assessed through the Mauchly test. Once the prerequisites for the use of parametric tests were verified, we used a univariate ANOVA to test the existence of significant $\mathrm{VO}_{2}$ differences between sessions and repeated measures ANOVA (11 tracks $\times 3$ sessions) to assess the existence of differences between resting $\mathrm{VO}_{2}$ and post-exercise recovery $\mathrm{VO}_{2}$. A Bonferroni test was performed. We carried out an estimate of the effect size through the partial eta-squared values $\left(\mu_{\mathrm{p}}{ }^{2}\right)$ in accordance with [27]. Using the Pearson correlation, we also analyzed the relation between $\mathrm{VO}_{2}$ across the three different sessions (mean $\mathrm{VO}_{2}$ over the three sessions was used in the correlation analysis). The level of significance was set at $p=0.05$.

\section{Results}

During IC sessions it was observed that there was a time main effect for absolute $\mathrm{VO}_{2}\left(\mathrm{VO}_{2} \mathrm{Abs}\right)$ and for relative $\mathrm{VO}_{2}\left(\mathrm{VO}_{2}\right.$ rel $)\left(\mathrm{F}_{(10,330)}=254.395 ; p<0.0001 ; \mu_{\mathrm{p}}{ }^{2}=0.885\right.$ and $\mathrm{F}_{(10,330)}=273.512$; $p<0.0001 ; \mu_{\mathrm{p}}^{2}=0.892$, respectively), a time $\mathrm{x}$ session interaction in the $\mathrm{VO}_{2} \mathrm{Abs}\left(\mathrm{F}_{(20,330)}=1.864\right.$; $\left.p=0.014 ; \mu_{\mathrm{p}}{ }^{2}=0.102\right)$, and a session effect both in $\mathrm{VO}_{2} \mathrm{Abs}$ and in $\mathrm{VO}_{2}$ rel $\left(\mathrm{F}_{(1,33)}=6.376 ; p=0.005\right.$; $\mu_{\mathrm{p}}{ }^{2}=0.279$ and $\mathrm{F}_{(1,33)}=7.980 ; p=0.001 ; \mu_{\mathrm{p}}{ }^{2}=0.326$, respectively). A significantly higher level of $\mathrm{VO}_{2} \mathrm{Abs}$ was observed in the $\mathrm{VO}_{2}$ session compared with the HR session $(p=0.004)$ and of $\mathrm{VO}_{2}$ rel in the $\mathrm{VO}_{2}$ session compared to that of the HR session $(p=0.001)$ and the RPE session $(p=0.042)$ (see Table 2). In all sessions, $\mathrm{VO}_{2} \mathrm{Abs}$ and $\mathrm{VO}_{2}$ rel were significantly higher $(p<0.05)$ during tracks (see Table 3) 4, 7, and 10 of the exercise protocols, when compared with that of the other tracks, and track 1 showed significantly lower levels $(p<0.05)$ (see Table 3). As for the mean session $\mathrm{VO}_{2}$, significantly lower levels of $\mathrm{VO}_{2} \mathrm{Abs}(p=0.007)$ were observed during the HR session compared with the $\mathrm{VO}_{2}$ session. Significantly higher levels of $\mathrm{VO}_{2}$ rel were also observed in the $\mathrm{VO}_{2}$ session compared with the HR session and the RPE session ( $p=0.001$ and $p=0.04$, respectively).

Table 2. Means and standard deviations of absolute $\left(\mathrm{VO}_{2} \mathrm{Abs}\right)$ and relative $\left(\mathrm{VO}_{2}\right.$ rel $)$ oxygen uptake, heart rate (HR), and respiratory exchange ratio (RER) in the three sessions.

\begin{tabular}{cccc}
\hline & VO $_{2}$ & HR & RPE \\
\hline $\mathrm{VO}_{2} \mathrm{Abs}(\mathrm{l} / \mathrm{min})$ & $2.33 \pm 0.27$ & $1.98 \pm 0.20^{*}$ & $2.10 \pm 0.29$ \\
$\mathrm{VO}_{2}$ rel $(\mathrm{ml} / \mathrm{kg} / \mathrm{min})$ & $30.09 \pm 3.18$ & $25.49 \pm 1.84^{*}$ & $27.12 \pm 3.14^{*}$ \\
$\mathrm{HR}(\mathrm{beat} / \mathrm{min})$ & $137.77 \pm 7.32$ & $130.85 \pm 6.56$ & $134.71 \pm 8.34$ \\
$\mathrm{RER}$ & $1.17 \pm 0.32$ & $1.24 \pm 0.18$ & $1.22 \pm 0.26$
\end{tabular}

* $p<0.05$ compared to the control session; $\mathrm{VO}_{2}$-session in which effort intensity was controlled through $\mathrm{VO}_{2}$; $\mathrm{HR}$-session in which intensity control was carried out through HR; RPE-session in which intensity control was carried out through OMNI-Cycle.

Table 3. Means and standard deviations of absolute $\left(\mathrm{VO}_{2} \mathrm{Abs}\right)$ and relative $\left(\mathrm{VO}_{2}\right.$ rel $)$ oxygen uptake during three sessions.

\begin{tabular}{ccccccc}
\hline \multicolumn{2}{c}{$\mathbf{V O}_{2}$} & \multicolumn{2}{c}{ HR } & \multicolumn{2}{c}{ RPE } \\
\hline & $\begin{array}{c}\text { Absolute } \\
(\mathbf{l} / \mathbf{m i n})\end{array}$ & $\begin{array}{c}\text { Relative } \\
(\mathbf{m l} / \mathbf{k g} / \mathbf{m i n})\end{array}$ & $\begin{array}{c}\text { Absolute } \\
(\mathbf{l} / \mathbf{m i n})\end{array}$ & $\begin{array}{c}\text { Relative } \\
(\mathbf{m l} / \mathbf{k g} / \mathbf{m i n})\end{array}$ & $\begin{array}{c}\text { Absolute } \\
(\mathbf{l} / \mathbf{m i n})\end{array}$ & $\begin{array}{c}\text { Relative } \\
(\mathbf{m l} / \mathbf{k g} / \mathbf{m i n})\end{array}$ \\
\hline T1 & $1.08 \pm 0.16^{*}$ & $13.83 \pm 1.28^{*}$ & $0.98 \pm 0.21^{*}$ & $12.79 \pm 2.54^{*}$ & $0.95 \pm 0.17^{*}$ & $12.24 \pm 1.65^{*}$ \\
T2 & $1.62 \pm 0.24$ & $20.87 \pm 2.61$ & $1.39 \pm 0.35$ & $18.38 \pm 4.60$ & $1.24 \pm 0.18$ & $15.92 \pm 1.98$ \\
T3 & $2.54 \pm 0.38$ & $32.71 \pm 3.18$ & $2.13 \pm 0.35$ & $28.56 \pm 4.53$ & $2.16 \pm 0.29$ & $27.81 \pm 2.88$ \\
T4 & $2.97 \pm 0.41 \&$ & $38.37 \pm 4.11 \&$ & $2.73 \pm 0.41 \&$ & $35.39 \pm 4.83 \&$ & $2.68 \pm 0.31 \&$ & $34.48 \pm 2.84 \&$ \\
T5 & $2.26 \pm 0.30$ & $27.95 \pm 4.37$ & $2.04 \pm 0.42$ & $25.37 \pm 4.71$ & $1.66 \pm 0.36$ & $22.86 \pm 4.07$ \\
T6 & $2.54 \pm 0.33$ & $32.96 \pm 3.99$ & $2.16 \pm 0.40$ & $29.20 \pm 4.41$ & $2.04 \pm 0.34$ & $25.87 \pm 3.49$ \\
T7 & $2.97 \pm 0.38 \&$ & $38.43 \pm 4.42 \&$ & $2.75 \pm 0.36 \&$ & $35.65 \pm 3.61 \&$ & $2.64 \pm 0.20 \&$ & $34.47 \pm 3.39 \&$ \\
T8 & $1.85 \pm 0.36$ & $25.17 \pm 4.77$ & $1.72 \pm 0.33$ & $20.78 \pm 3.25$ & $1.48 \pm 0.28$ & $18.81 \pm 2.62$ \\
T9 & $2.43 \pm 0.36$ & $31.51 \pm 4.93$ & $2.00 \pm 0.37$ & $26.99 \pm 3.84$ & $1.97 \pm 0.28$ & $26.23 \pm 3.17$ \\
T10 & $2.85 \pm 0.34 \&$ & $36.94 \pm 4.92 \&$ & $2.60 \pm 0.29 \&$ & $33.82 \pm 3.73 \&$ & $2.51 \pm 0.31 \&$ & $32.30 \pm 3.87 \&$ \\
T11 & $1.85 \pm 0.40$ & $22.37 \pm 5.93$ & $1.62 \pm 0.37$ & $20.89 \pm 4.25$ & $1.64 \pm 0.36$ & $19.78 \pm 4.15$ \\
\hline
\end{tabular}

* $p<0.05$ compared with the other tracks; and \& $p<0.05$ compared with the other tracks with the exception of the tracks 4, 7, and 10; $\mathrm{VO}_{2}$-session in which effort intensity was controlled through $\mathrm{VO}_{2} ; \mathrm{HR}$-session in which intensity control was carried out through HR; RPE—-session in which intensity control was carried out through OMNI-Cycle. 
Statistically significant $(p<0.0001)$ correlations in $\mathrm{VO}_{2}$ rel were also observed between the mean $\mathrm{VO}_{2}$ session and mean RPE session (0.986), between the mean $\mathrm{VO}_{2}$ session and mean HR session (0.977), and between the mean HR session and mean RPE session (0.992).

\section{Discussion}

The aims of this investigation were to determine if HR and RPE can be used to control exercise intensity and which method of intensity control, HR or RPE, better correlates with the oxygen uptake during an IC class. The present results suggest RPE and HR self-regulate exercise intensity during an intensive interval method with trained subjects: Indeed, both methods (HR and RPE) resulted in $\mathrm{VO}_{2}$ that was lower than in the $\mathrm{VO}_{2}$ session. However, results of the correlational analysis revealed a strong relation $(p<0.0001)$ between mean $\mathrm{VO}_{2}$ in the $\mathrm{VO}_{2}$ and $\mathrm{HR}$ sessions $(r=0.997)$ and between mean $\mathrm{VO}_{2}$ in the $\mathrm{VO}_{2}$ and RPE sessions $(r=0.986)$. Based on these results, it appears that subjects experienced in IC can use RPE or HR to control exercise intensity in classes with methodological characteristics similar to those used in this study. Although, the intensity obtained through RPE or HR are relatively lower than $\mathrm{VO}_{2}$.

The results of the present study do not corroborate previous studies, [3-5,22], which suggested using HR, not RPE, in order to control intensity in an IC class. This may result from the fact that the previous sample [22] consisted of subjects inexperienced in IC or that, in the studies [3-5,22] RPE assessment took place at the end of the class rather than during each track. Because of this, an intensity in these studies was not controlled by RPE but established using average HR and RPE at the end of the IC session. In order to increase reliability of the results, it's necessary that participants learn the RPE scale. Soriano-Maldonado et al. [21] showed an increase in correlation between HR and RPE when they compared the first IC class with the fifth class. These results corroborate with the study of Chen et al. [28], which shows that it's necessary to associate the RPE scale with the task, in this case with IC classes. Finally, another methodological aspect that could explain the difference between the results of the present study and the previously cited studies was that maximal HR (HRmax) was calculated and not measured during maximal tests. This indirect calculation is based on age and may result in an under- or overestimated HRmax [3,22].

It is important to point out that we used an interval-training class in this study as that is generally consistent with IC classes. During this kind of effort, HR has a slow response to intensity changes [14]. However, if a constant intensity is used while carrying out the exercise, this problem does not occur, and HR will remain stable during the entire workout session, enabling HR to be reliably and safely used for intensity control [14]. In the present study, we noticed that a session controlled through HR, despite displaying lower levels of $\mathrm{VO}_{2} \mathrm{Abs}$ and $\mathrm{VO}_{2}$ rel than those of the control session, presented values of $\mathrm{VO}_{2}$ that strongly correlated with the $\mathrm{VO}_{2}$ values presented in the $\mathrm{VO}_{2}$ session $(r=0.977$, $p<0.0001)$. A similar response was observed in the RPE session $(r=0.986, p<0.0001)$. Therefore, for intensity control, the use of HR or RPE both appear to be effective for trained subjects who have similar characteristics as the sample in this study.

As in this study, the use of RPE has been previously proven to be effective in controlling effort intensity during intermittent exercise sessions conducted on various modalities, such as fitness circuits [29], and in the carrying out of activities of constant intensity commonly used to improve aerobic capacity using ergometers [30]. It seems that proper correlation to the RPE scale is an important factor regarding the effectiveness of using RPE to control intensity.

We conclude that HR and RPE can be used to self-regulate exercise intensity during IC classes. However, both variables result in a $\mathrm{VO}_{2}$ that is lower than the criterion measure. The form of intensity control that correlates most strongly with $\mathrm{VO}_{2}$ is $\mathrm{RPE}(r=0,986)$; however, $\mathrm{HR}(r=0,977)$ also shows a strong correlation with $\mathrm{VO}_{2}$. 


\section{Conclusions}

Based on the results of this study, trained subjects can use either RPE or HR to control intensity in IC classes. More research with different populations and IC class methodologies is needed to clarify if the RPE can be effectively used to control the exercise intensity.

\section{Practical Application}

Instructors and coaches can use the RPE in trained subjects as a cheaper, effective way to control the intensity of IC sessions. However, IC instructors must be warned that RPE underestimates the intensity of IC session as does using HR.

Author Contributions: Conceptualization, R.C.-L., J.V.-A, F.G., and V.M.R.; methodology, J.V.-A. and V.M.R.; investigation, R.C.-L., T.M., R.P., N.G., H.F., and V.M.R.; data curation, F.G. and V.M.R.; writing-original draft preparation, R.C.-L., J.V.-A., and V.M.R.; writing-review and editing, N.G. and V.M.R.; supervision, J.V.-A.; project administration, V.M.R.; All authors have read and agreed to the published version of the manuscript.

Funding: This work is supported by national funding through the Portuguese Foundation for Science and Technology, I.P., under project UID04045/2020

Conflicts of Interest: The authors declare no conflict of interest.

\section{References}

1. Norton, K.; Norton, L.; Sadgrove, D. Position statement on physical activity and exercise intensity terminology. J. Sci. Med. Sport 2010, 13, 496-502. [CrossRef] [PubMed]

2. Golderg, J. Spinning ${ }^{\circledR}$ Instructor Manual. Phase 1: The Spinning ${ }^{\circledR}$ Journey 1.01; Schwinn Fitness International: Givisiez, Switzerland, 1996.

3. Muyor, J.M. Exercise Intensity and Validity of the Ratings of Perceived Exertion (Borg and OMNI Scales) in an Indoor Cycling Session. J. Hum. Kinet. 2013, 39, 93-101. [CrossRef] [PubMed]

4. Caria, M.A.; Tangianu, F.; Concu, A.; Crisafulli, A.; Mameli, O. Quantification of Spinning bike performance during a standard 50-minute class. J. Sports Sci. 2007, 25, 421-429. [CrossRef] [PubMed]

5. Battista, R.A.; Foster, C.; Andrew, J.; Wright, G.; Lucia, A.; Porcari, J.P. Physiologic responses during indoor cycling. J. Strength Cond. Res. 2008, 22, 1236-1241. [CrossRef]

6. Dias, M.R.C.; Silva, A.C.E.; Júnior, J.M.N.; Batista, L.A.; de Lima, J.R.P.; da Silva Novaes, J. Effect of pedal cadence on mechanical power output and physiological variables. Braz. J. Kinanthropometry Hum. Perform. 2007, 9, 271-276. [CrossRef]

7. Barbosa, T.M.; Sousa, V.F.; Silva, A.J.; Reis, V.M.; Marinho, D.A.; Bragada, J.A. Effects of musical cadence in the acute physiologic adaptations to head-out aquatic exercises. J. Strength Cond. Res. 2010, 24, 244-250. [CrossRef]

8. Arngrímsson, S.A.; Stewart, D.J.; Borrani, F.; Skinner, K.A.; Cureton, K.J. Relation of heart rate to percent VO2 peak during submaximal exercise in the heat. J. Appl. Physiol. 2003, 94, 1162-1168. [CrossRef]

9. Rowell, L.B. Human cardiovascular adjustments to exercise and thermal stress. Physiol. Rev. 1974, 54, 75-159. [CrossRef]

10. Ramos-Jiménez, A.; Hernández-Torres, R.P.; Wall-Medrano, A.; Torres-Durán, P.V.; Juárez-Oropeza, M.A.; Solis Ceballos, J.A. Acute physiological response to indoor cycling with and without hydration; case and self-control study. Nutr. Hosp. 2013, 28, 1487-1493. [CrossRef]

11. da Silva, S.A.F.; Guida, H.L.; dos Antonio, A.M.; de Abreu, L.C.; Monteiro, C.B.M.; Ferreira, C.; Ribeiro, V.F.; Barnabe, V.; Silva, S.B.; Fonseca, F.L.A.; et al. Acute Auditory Stimulation with Different Styles of Music Influences Cardiac Autonomic Regulation in Men. Int. Cardiovasc. Res. J. 2014, 8, 105-110.

12. Shaulov, N.; Lufi, D. Music and light during indoor cycling. Percept. Mot. Skills 2009, 108, 597-607. [CrossRef] [PubMed]

13. Carneiro, A.L.; Oliveira, G.R.; Matos, D.G.; Aidar, F.; Manzini-Filho, M.L.; Hickner, R.C.; Reis, V.M. Physiological response to fluid intake with and without carbohydrate during indoor cycling classes. Gazz. Med. Ital. Arch. Sci. Med. 2014, 173, 291-298.

14. Tschakert, G.; Kroepfl, J.; Mueller, A.; Moser, O.; Groeschl, W.; Hofmann, P. How to Regulate the Acute Physiological Response to "Aerobic" High-Intensity Interval Exercise. J. Sports Sci. Med. 2015, 14, $29-36$. 
15. Eston, R.G.; Lamb, K.L.; Parfitt, G.; King, N. The validity of predicting maximal oxygen uptake from a perceptually-regulated graded exercise test. Eur. J. Appl. Physiol. 2005, 94, 221-227. [CrossRef] [PubMed]

16. Robertson, R.J.; Goss, F.L.; Bell, J.A.; Dixon, C.B.; Gallagher, K.I.; Lagally, K.M.; Timmer, J.M.; Abt, K.L.; Gallagher, J.D.; Thompkins, T. Self-regulated cycling using the Children's OMNI Scale of Perceived Exertion. Med. Sci. Sports Exerc. 2002, 34, 1168-1175. [CrossRef] [PubMed]

17. Robertson, R.J.; Noble, B.J. Perception of physical exertion: Methods, mediators, and applications. Exerc. Sport Sci. Rev. 1997, 25, 407-452. [CrossRef] [PubMed]

18. Shinya Yamauchi, S.M. Rating of Perceived Exertion for Quantification of the Intensity of Resistance Exercise. Int. J. Phys. Med. Rehabil. 2013, 1, 1-4. [CrossRef]

19. Robertson, R.J.; Goss, F.L.; Dube, J.; Rutkowski, J.; Dupain, M.; Brennan, C.; Andreacci, J. Validation of the adult OMNI scale of perceived exertion for cycle ergometer exercise. Med. Sci. Sports Exerc. 2004, 36, 102-108. [CrossRef]

20. Nakamura, F.Y.; Pereira, G.; Chimin, P.; Siqueira-Pereira, T.A.; Simões, H.G.; Bishop, D.J. Estimating the perceived exertion threshold using the OMNI scale. J. Strength Cond. Res. 2010, 24, 1602-1608. [CrossRef]

21. Soriano-Maldonado, A.; Romero, L.; Femia, P.; Roero, C.; Ruiz, J.R.; Gutierrez, A. A learning protocol improves the validity of the Borg 6-20 RPE scale during indoor cycling. Int. J. Sports Med. 2014, 35, 379-384. [CrossRef]

22. López-Miñarro, P.A.; Muyor Rodríguez, J.M. Heart rate and overall ratings of perceived exertion during Spinning ${ }^{\circledR}$ cycle indoor session in novice adults. Sci. Sports 2010, 25, 238-244. [CrossRef]

23. Balke, B.; Ware, R.W. An experimental study of physical fitness of Air Force personnel. U.S. Armed Forces Med. J. 1959, 10, 675-688. [PubMed]

24. American College of Sport Medicine ACSM's Guidelines for Exercise Testing and Prescription, 9th ed.; Lippincott Williams \& Wilkins: Philadelphia, PA, USA, 2014; ISBN 978-1-60913-605-5.

25. Jackson, A.S.; Pollock, M.L. Generalized equations for predicting body density of men. Br. J. Nutr. 1978, 40, 497-504. [CrossRef] [PubMed]

26. Siri, W.E. Body composition from fluid spaces and density: Analysis of methods. 1961. Nutr. Burbank Los Angel. Cty. Calif 1993, 9, 480-491; discussion 480-492.

27. Fritz, C.O.; Morris, P.E.; Richler, J.J. Effect size estimates: Current use, calculations, and interpretation. J. Exp. Psychol. Gen. 2012, 141, 2-18. [CrossRef] [PubMed]

28. Chen, M.J.; Fan, X.; Moe, S.T. Criterion-related validity of the Borg ratings of perceived exertion scale in healthy individuals: A meta-analysis. J. Sports Sci. 2002, 20, 873-899. [CrossRef]

29. Aniceto, R.R.; Ritti-Dias, R.M.; Dos Prazeres, T.M.P.; Farah, B.Q.; de Lima, F.F.M.; do Prado, W.L. Rating of Perceived Exertion During Circuit Weight Training: A Concurrent Validation Study. J. Strength Cond. Res. 2015, 29, 3336-3342. [CrossRef]

30. Scherr, J.; Wolfarth, B.; Christle, J.W.; Pressler, A.; Wagenpfeil, S.; Halle, M. Associations between Borg's rating of perceived exertion and physiological measures of exercise intensity. Eur. J. Appl. Physiol. 2013, 113, 147-155. [CrossRef]

(C) 2020 by the authors. Licensee MDPI, Basel, Switzerland. This article is an open access article distributed under the terms and conditions of the Creative Commons Attribution (CC BY) license (http://creativecommons.org/licenses/by/4.0/). 